\title{
PENSATA
}

http://dx.doi.org/10.1590/So034-759020140511

\section{UM APROFUNDAMENTO PARA 0 CONCEITO DE ÉTICA DIGITAL}

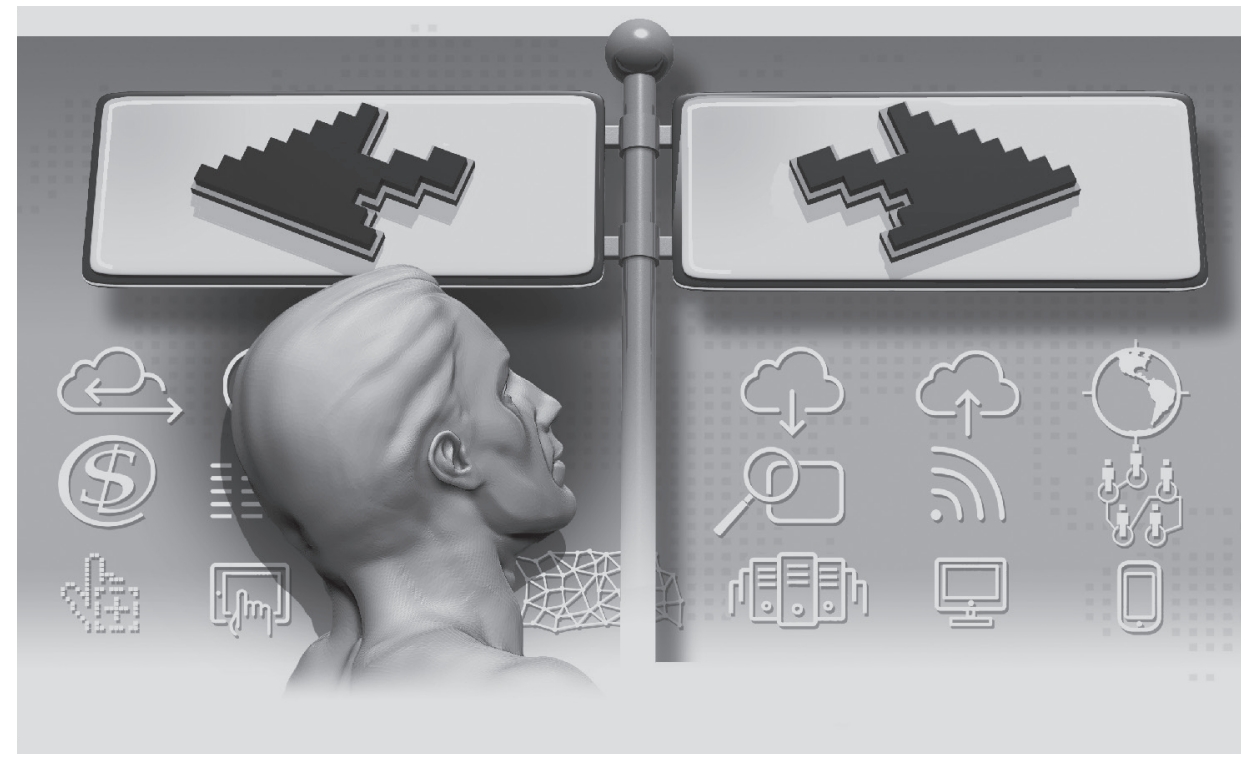

Da governança da internet ao teletrabalho, da exclusão digital à privacidade e aos crimes informáticos (Guardo, Maggiolini, \& Patrignani, 2010), há temas diversos que podem ser elencados como parte do que seja e o que inclua Ética Digital, a "ética da era da informática". Antes de examinar algumas desses temas de grande importância e atualidade, precisamos perguntar se há um fator comum, um “princípio unificante”, para a Ética Digital.

\section{Sobre a essência da ética}

Quando pensamos em ética, em todos os seus sentidos, partimos da premissa de que estamos abordando a característica fundamental que distingue os seres humanos dos não humanos. Creio ser plenamente admissível a ideia de muitos filósofos que tratam a liberdade com base na sua intrínseca dimensão ética, e não na racionalidade. Essa liberdade sofre muitos tipos de restrições, mas existe sempre, portanto pode ser exercida. Sem liberdade não se pode falar de ética, mas de determinismo - biológico ou histórico social - e ainda menos se poderia falar de responsabilidade e, consequentemente, de ética. Essa responsabilidade se manifesta, segundo Ricoeur (1955), em maneira direta, em relações interpessoais imediatas (curtas), ou em maneira indireta, em relações por intermédio de instituições ou do ambiente (longas).

PIERCARLO MAGGIOLINI

piercarlo.maggiolini@polimi.it

Professor da School of Management,

Politecnico di Milano - Milão, Itália

\section{Necessidade de uma nova ética}

A segunda premissa parte da necessidade de propormos um fundamento para a pesquisa e a adoção de uma Ética Digital. Poderíamos dizer, como Jonas (1979), que a "civilização tecnoló- 
gica" em que vivemos - uma civilização realmente "nova", em que as tecnologias de informação e comunicação (TIC) têm um papel vital e crescente - apela a uma "nova ética" focada no "princípio de responsabilidade". Será que, no passado, as pessoas eram menos responsáveis e que só agora, por alguma razão, deveriam tornar-se mais responsáveis? Essa razão não seria puramente teórica, dada a crescente complexidade dos fenômenos econômicos e sociais.

Acontece, porém, exatamente o contrário. Antigamente era muito mais fácil ser responsável eticamente e socialmente. Bauman (2002) afirma que os nossos antepassados eram testemunhas diretas de quase todas as consequências de seus atos, porque os acontecimentos e suas consequências muito raramente saíam do campo visual ou do seu raio de ação direta. Segundo Bauman (2002), “Com o início da nova e crescente rede global de dependências e de uma tecnologia suficientemente poderosa para produzir consequências de nível global - essa situação moralmente satisfatória se extinguiu”.

As gerações que nos precederam - intencionalmente ou não - eram conscientes das consequências de suas ações porque as vivenciavam no tempo e no espaço de suas vidas. Consequentemente tinham também na consciência uma relação de causa-efeito entre ação e consequência e eram obrigadas a considerá-la. Hoje a questão mudou muito: falta a plena consciência do efeito das novas tecnologias. Isso ocorre desde a manipulação genética, passando por todas as novas tecnologias que incluem as da informação. Poucas das nossas ações nesta sociedade tecnológica globalizada são acompanhadas da consciência das consequências, e isso não permite uma reflexão ética. Nem mesmo os criminosos informáticos conhecem a suas vítimas (um exemplo é o phishing). Por essa razão, só uma parte relativamente pequena das nossas ações ou omissões é guiada pelos valores e sentimentos morais. Poucos estão em condições de considerar os possivveis efeitos de suas ações sobre os outros, a menos que tomem parte diretamente nessas ações.

Evidentemente, esta situação é insustentável. Estamos na direção de uma sociedade de irresponsabilidade social generalizada! Entretanto, não é admissível que se possa causar danos imensos em momentos e lugares tão diversos - sem mesmo ter consciência disso - apenas porque estamos submersos numa interdependência fora de nosso controle. 0 teórico da sociedade de risco, Ulrich Beck (1992), diz que devemos nos conscientizar para o fato de não existirem soluções individuais para contradições coletivas. A nova Ética Digital, não pode ser uma ética unicamente individual, mas deve ser sobretudo uma ética coletiva, pública e profissional.

\section{Por um princípio unificante para a Ética Digital}

Uma visão da história da tecnologia da informação pode ajudar muito a estabelecer um princípio unificante da Ética Digital, tanto em termos de sua criação quanto das necessidades às quais deveria responder. Os desafios éticos e sociais das novas TIC têm origem nas mesmas razões pelas quais tais tecnologias se difundiram, assim como é o caso do automóvel, da energia nuclear etc. 0 desafio é também criar um equilíbrio que nos seja favorável nos inevitáveis dualismos: claro - escuro; vantagem - desvantagem; ou, ainda, custo - beneficio do desenvolvimento tecnológico.

Como analogia, vejamos um exemplo do passado: a invenção da escrita, a primeira tecnologia da informação criada pela hu manidade (Maggiolini, 2010a). Bem como qualquer outra tecnologia da informação posterior, a escrita permitiu o acesso, a difusão e a memorização do conhecimento, aumentando a capacidade da memória humana. Se pesquisarmos os usos iniciais e a difusão da informática, a analogia com a escrita é impressionante. Hoje, a informática é mais usada não para a gestão de bibliotecas ou para a elaboração de dados científicos, mas no campo econômico-financeiro. Da mesma forma, a escrita não foi originalmente criada para escrever a llíada, que se prestava mais à tradição oral, mas para escrever... faturas!

Além de aumentar a memória humana, a difusão das TIC tem, portanto, duas origens: o controle da crescente complexidade, pois precisamos cada vez mais de informações e de tecnologia para gerenciá-la; e a falta de confiança gerada pelo oportunismo e a consequente necessidade de controle das relações humanas, não apenas as comerciais. Nas sociedades mais simples, nas quais as pessoas se conhecem diretamente, o controle social é mais fácil e, portanto, requer menos informações (e TICs), porque existem outros meios para controlar o oportunismo. Nas sociedades mais complexas, se existisse mais confiança entre as pessoas, seria possível exercer um menor controle, e também menos TICs.

Assim, o "princípio unificante" que descreve o uso e a difusão da tecnologia da informação e que permite de enquadrar a chamada Ética Digital é baseado em dois fatores relacionados à necessidade da informação e das suas tecnologias: um que podemos chamar de complexidade técnica e outro de complexidade política. 0 primeiro é diretamente proporcional ao nível de complexidade dos processos (e dos fenômenos) que se quer conhecer e controlar, seja numa organização, na economia ou na sociedade. O segundo é inversamente proporcional ao nível de confiança entre os agentes envolvidos nesses processos.

Os problemas ético-sociais relacionados com as tecnologias da informação se entrelaçam fortemente e aumentam junto com a complexidade técnica e a complexidade política. Em outras palavras, as TIC, ao mesmo tempo que fornecem soluções cada vez mais eficazes para dominar as comple- 
xidades técnica e política, geram novos desafios e questões ético-sociais mais graves e difíceis de resolver.

Para esclarecimento, basta um exemplo: a privacidade. 0 aumento da complexidade econômica e social (complexidade técnica) e do crescimento da falta de confiança nas relações comerciais e públicas (complexidade política) na sociedade pós-industrial (Maggiolini, 2010b) poderia ser resolvido de duas maneiras distintas. A primeira requer que as responsabilidades sociais sejam assumidas com maior consciência. A segunda é aumentar o controle - direto e/ou indireto - sobre as pessoas, o que a tecnologia certamente poderia fornecer, mas à custa da violação da privacidade.

Assim, diante do possível beneficio oferecido pelo maior controle, cria-se um problema ético-social pela crescente violação da privacidade. Isso requer uma adequada ética relativa à TIC. Além disso, a complexidade "técnica" exige uma ética profissional adequada dos agentes envolvidos, porque os riscos técnicos de mau funcionamento são muito elevados.

Podemos ligar o princípio unificante da Ética Digital aos temas éticos da "sociedade da informação” (Guardo et al., 2010). Uma sociedade de crescente complexidade, sobretudo no campo econômico (pela globalização, especialmente das finanças e da produção) gera e multiplica a necessidade de informação para o gestão e o controle dessa mesma complexidade, em menor ou maior grau satisfeita pela TIC.

0 mesmo princípio unificante também se relaciona com o tema do e-Government (Fugini et al., 2005) e da e-Democracy (Cindio \& Peraboni, 2010). 0 e-Government (governo eletrônico) é uma tentativa de um governo público da complexidade (uma promessa, mais que uma ação efetiva). A complexidade "criminal", por razões de segurança, seria também objeto de uma tentativa de controle com base nas TIC, com todos os problemas que isso acarreta. A isso responde, e corresponde, a e-Democracy (democracia eletrônica) no seu papel de controle e participação democrática nos processos sempre mais complexos de governo.

Podemos incluir a proteção da propriedade intelectual (Johns, 2009) ao princípio unificante da Ética Digital, na medida em que se apresente como uma questão de (difícil) controle contra o oportunismo de se apoderar das ideias alheias para ganhar dinheiro, seja com bens de natureza intelectual ou com privatização de bens intelectuais comuns. Não é por acaso que foram propostos os creative commons, que correspondiam, na Idade Média, à propriedade pública, ou de uma comunidade. Num mercado de ideias, a proteção da propriedade intelectual é obviamente superada em larga escala por bens intelectuais baseados na reciprocidade, como nos casos do Software Livre, da Wikipedia etc.

\section{Implicações ético-sociais das tendências das TIC}

Podemos considerar três dimensões fundamentais das TIC: elaborar informações, memorizar informações e transmitir informações. Baseados nessas dimensões, podemos avaliar as principais tendências das TIC, que já causam implicações ético-sociais. Essas três dimensões em formidável desenvolvimento, antes consideradas parcialmente distintas, há muito se fundiram, criando novas questões problemáticas, porque da quantidade se desenvolve a qualidade.

Há décadas, a potência de cálculo dos dispositivos relacionados às TIC continua a duplicar em muito pouco tempo, e chega-se a afirmar que essa duplicação ocorre a cada 18 meses. Se as TIC melhoram nossa capacidade de memorização, a evolução constante das técnicas de análise de dados implica diretamente a queda dos custos de memorização. As conexões de rede e a capacidade de transmissão de informação têm melhorado continuamente, particularmente após o estabelecimento da internet.
Essas macrotendências indicam que as atividades econômicas, científicas e militares, para citar algumas, demonstram uma crescente dependência das TIC, análoga à dependência da energia elétrica. Ao aumentar assustadoramente a dependência dos sistemas informáticos e, portanto, a nossa vulnerabilidade, as questões vitais revelam-se aquelas do backup, da segurança dos sistemas e de como nos proteger do seu mau funcionamento.

Não é por acaso que as leis de proteção da privacidade foram criadas depois da difusão das TIC, e não há milhares de anos. Embora a preocupação com a privacidade seja precedente às $\mathrm{TIC}$, foi a sua difusão em larga escala que deu origem à questão da proteção da privacidade. $E$ as perspectivas nesse campo são cada vez mais críticas. Por exemplo, com o cloud computing, não se sabe onde se guardam dados, confia-se apenas nos provedores que gerenciam os servidores digitais.

Essa evolução também torna mais fácil e barato do que nunca violar a propriedade intelectual, seja copiando um filme, gravando música, obtendo livros inteiros. Também nas universidades o plágio tornou-se um problema inacreditável, exatamente porque nunca foi tão fácil copiar.

As TIC estão revolucionando a localização do trabalho. Essa deslocalização (com os consequentes problemas ocupacionais), que era restrita à produção manufatureira, tornou-se universal, inclusive nos serviços financeiros. Um caso típico é o dos call centers, em que um serviço fornecido na Itália pode ter origem na Hungria, Romênia ou Albânia, quando se pode, às vezes, reconhecer esse processo pelo sotaque dos atendentes.

\section{Problemas emergentes da Ética Digital}

Um mapa interessante dos principais temas de Ética Digital foi proposto por Patrignani (2009). Além dos já mencionados problemas relacionados à privacidade, à proprie- 
dade intelectual, à e-democracy e à deslocalização, podemos destacar muitos outros temas críticos da Ética Digital, como governança da internet, guerra cibernética, cyberterrorismo e crimes digitais.

Não é o caso de detalhar cada tema singularmente. Gostaria de selecionar apenas três dos mais importantes e ainda pouco considerados. 0 primeiro é a transmissão do conhecimento: a ética das ferramentas de busca. 0 segundo tema é a gestão das transações financeiras de alta frequência. O terceiro é o problema da e-reputation, ou seja, da reputação na rede, um problema muito delicado e importante o qual não se discute o suficiente, especialmente perante a rapidíssima difusão do uso das redes sociais.

\section{Transmissão do conhecimento e ética das ferramentas de busca}

Uma novidade absoluta e crucial é a ética dos motores de busca (Hinman, 2005), que representam desafios para a difusão do conhecimento. Os instrumentos principais de acesso ao conhecimento, obviamente no sentido de informações superficiais ou muito específicas, e não, com certeza, no sentido de aprofundamento, de sabedoria, são as ferramentas de busca.

A ética das ferramentas de pesquisa e a transmissão do conhecimento representam problemas de confiabilidade, competência na pesquisa, e até mesmo da capacidade cognitiva do usuário. A transmissão do conhecimento que se faz usando as ferramentas de busca constitui, hoje em dia, um grande problema. Temos à disposição, potencialmente, milhões de páginas sobre um tema, apresentadas numa ordem que não se conhece claramente de onde vem.

Citando Carr (2008), em 1964, nos Estados Unidos, $81 \%$ dos adultos liam diariamente um jornal. No ano 2000 , esse número diminuiu $50 \%$, porque agora as pessoas usam outros meios (digitais) para obter informações. Entre os jovens, os leitores de jornal em papel diminuíram muito (caindo dos $73 \%$ em 1970 a 36\% em 2006), substituídos por outros canais de informação.

Os jornais cotidianos e de assuntos gerais são essencialmente um pacote único, uma entidade com várias facetas que vão da política ao esporte, da crônica às finanças etc. É claro que nem todos leem tudo, mas os jornais são concebidos como uma entidade única. O objetivo do editor é garantir que o pacote completo atraia um grupo de leitores e investidores em publicidade o mais heterogêneo possível. O jornal, como produto, vale mais do que a soma de suas partes.

Na rede, qual é a diferença? Em geral, a informação nos jornais on-line também é financiada pela publicidade, cujo preço depende das visualizações e dos cliques. Algumas publicações são pagas, sobretudo as revistas científicas (por enquanto...) e alguns dos jornais de prestígio. Só uma parte do jornal é acessível gratuitamente, mas a maioria dos leitores on-line lê só a parte gratuita, que é financiada diretamente pela publicidade.

Procura-se diretamente, sobretudo com as ferramentas de busca, o artigo que interessa. Cada artigo transforma-se em um produto em si. 0 jornal on-line torna-se uma soma de pedaços que devem, individualmente, justificar-se no nível econômico, porque é isso que, em última análise, serve para financiar o jornal. Nesse contexto, torna-se evidente que as reportagens de qualidade são laboriosas, caras e economicamente pouco rentáveis.

Teremos, então, o que Carr chama de "o grande desempacotamento". Em teoria, não seremos mais obrigados a pagar - nem mesmo indiretamente - por "detritos para procurar as coisas de valor”. Ou seja, a nós interessa somente o que a ferramenta busca, seleciona e apresenta, talvez selecionado não somente por filtros com um algoritmo (desconhecido), mas também personalizado em função do perfil do usuário, progressivamente definido pelas suas pesquisas precedentes. Não sabemos como, mas o algoritmo de busca é sensível ao usuário, portanto, em vez de aumentar a gama das informações fornecidas, concentra cada vez mais o espectro das informações buscadas. Assim, é verdade que temos uma grande quantidade de informações disponíveis, mas, se os filtros e mecanismos concentram as informações, teremos, na melhor das hipóteses, uma cultura vasta, mas de profundidade muito limitada, porque isso custa, e os textos longos não são muito apreciados no jornal on-line. Em última análise, teremos uma cultura concentrada.

Nesse caso, colocamos em evidência o problema da autoridade, ou da confiabilidade das informações, ou do conhecimento. Quem valida e seleciona as informações?

$\mathrm{Na}$ sociedade pré-internet, era claro: eram os formadores de opinião (cuja reputação, pelo menos, era conhecida), nos quais se incluem as mídia tradicionais, como jornais, rádio e TV, as revistas especializadas, mas sobretudo os respectivos editores e jornalistas. Existem as instituições culturais e os peritos, assim como as editoras, cuja seleção e controle das informações são feitos seguindo uma linha editorial. Esses intermediários têm uma reputação e devem prestar contas dela, porque é o capital em que baseia o seu trabalho.

Com a internet, o que acontece? A seleção das informações e do conhecimento passa a ser, em grande parte, de responsabilidade do usuário. Existirão todas as informações, mas o resto do resultado da busca (90\%?) são informações cuja procedência é desconhecida. Esse resultado da busca, mesmo que autêntico, e não um absurdo (como às vezes acontece, mesmo nos jornais), pode ser completamente alheio à busca original.

As ferramentas de busca, por causa de mecanismos indesejados, causam confusão, ou até a alteração das informações, portanto é o consumidor da informação o encarregado de a selecionar e controlar. $\mathrm{Na}$ formação das ideias, ou simplesmente 
na formação, tout court, a situação é muito diversa. Existe um contexto, ou um grupo, uma escola, com a qual se deve confrontar, entrar em conflito. Com isso, se verificam as suas próprias ideias, se estão num contexto totalmente oposto, ou se todos pensam do mesmo jeito, têm as mesmas tradições etc. A importância da escola - em todos os níveis, incluindo a universidade - é clara e evidente para propiciar esse confronto.

Com certeza, há aspectos positivos, como uma pesquisa focada e a exclusão automática das informações não desejadas, a possibilidade de tecer relações somente com quem compartilha os nossos interesses e ideais. Mas os aspectos negativos devem ser tomados em consideração: os riscos de um empobrecimento cognitivo, a perda de uma experiência comum compartilhada, e sobretudo o que poderíamos chamar a polarização, ou, em inglês, mais corretamente, homophily, com a qual se indicam as pessoas que pensam no mesmo modo. Esse fenômeno foi estudado no passado por um Prêmio Nobel da economia (Schelling, 1978), quando ainda não existia internet, mas que as redes sociais estão aumentando sem nenhum controle. Isso não é bom: conduz ao extremismos e ao radicalismo.

\section{High frequency trading, as negociações de alta frequência}

O segundo tema será abordado como um convite à reflexão. Quero focar o uso dos programas especiais no campo das finanças, o High Frequency Trading (HFT): sistemas para negociações de alta frequência. Esse tipo de negociação usa programas baseados em algoritmos que dão automaticamente ordens de compra e venda num determinado mercado.

Os HFT executam milhões de ordens em poucos segundos num contexto financeiro, na bolsa de valores, na maioria dos casos, mas também fora dele. 0 tempo necessário para uma aquisição on-line é de 0,03 milésimos de segundo. Atualmente $48,6 \%$ do volume de transações na bolsa é feito automaticamente com esses programas. Os HFT fizeram explodir o volume de negócio sem todas as bolsas do mundo ( $164 \%$ a mais só em Wall Street, desde 2005). Só a Goldman Sachs, por meio do HFT, mantém transações diárias de centenas de milhões de dólares.

$\mathrm{Na}$ verdade, são muito poucos os operadores que conhecem a fundo o procedimento em que se baseiam as operações de tais programas. Mesmo para os peritos, se é que existem peritos nesse campo, cria-se uma dependência muito forte da máquina. Os HFT não estabilizam as variações dos valores financeiros, pelo contrário, as amplificam. Esses programas são considerados um dos fatores que deram origem à crise financeira recente, não só acelerando e amplificando o seu percurso, mas também por meio de autênticas manipulações especulativas dos mercados.

Há efeitos positivos no uso dos HFT, como aumento da liquidez e da eficiência dos mercados e redução dos custos de transação. Entretanto, os efeitos negativos, como manipulação dos mercados, volatilidade, assimetria nas informações, dano aos pequenos investidores, efeito cascata e pró-cíclicos, podem superar os benefícios.

Um exemplo clássico é a manipulação especulativa. Essencialmente se lançam tantos pedidos de compras ao mesmo tempo em relação a uma série de títulos, no valor de milhões, o que aumenta a demanda desses títulos e o seu preço. Mas eles não são comprados, porque, imediatamente depois do lançamento, os pedidos são cancelados, graças à velocidade impressionante das transações. E como as transações efetivamente não ocorrem, isso permite não pagar pelo uso da plataforma. Os custos, por sinal altos, do uso dessa plataforma de TIC recaem sobre os que fizeram efetivamente as transações, e são estes a pagar pelo processo inteiro. Além disso, a operação de atrair a demanda sobre alguns títulos, fazendo-os aumentar de volume, causa a diminuição para outros, dando margem à especulação para jogar com o aumento a e diminuição fictícia de seus valores.

Com os HFT, é, enfim, possível mirar um título promissor, comprá-lo, vendê-lo, apoiá-lo, ou simplesmente atacá-lo, golpeá-lo e finalmente afundá-lo. Tudo isso em frações de segundo, intervalos infinitesimais que podem decidir o destino de uma empresa, garantindo aos especuladores ganhos estonteantes. Aos investidores, causa perdas graves. Aos especuladores, é possível gerar ataques na bolsa, transformando um título simplesmente em um número. Variáveis decisivas, como prospectivas de crescimento industrial, a situação financeira ou as possibilidades de dividendos, tornam-se simplesmente irrelevantes. Esse fenômeno já é conhecido, e os gestores de bolsa estão tentando regulamentar os HFT, porque é um grande risco para os mercados financeiros.

\section{E-reputação e direito ao esquecimento}

Com isso, chegamos ao terceiro tema, e-reputation (a reputação na rede), e ao correspondente direito ao esquecimento (Mayer-Schöneberger, 2009).

A reputação na rede, apesar de ser uma questão séria e delicada, é normalmente menosprezada. Pareceria um tema ligado à privacidade, mas só até um certo ponto, porque a privacidade envolve fundamentalmente o acesso a informações pessoais que não se tornaram públicas. A reputação na rede é ligada às informações públicas de uma pessoa qualquer, seja no caso em que a informação tenha sido posta na rede pela própria pessoa ou por terceiros. Não importa se é uma foto ou uma opinião manipulada. E os efeitos da (má e distorcida) reputação na rede podem ser traumáticos, devastadores.

Um exemplo é o caso de Stacy Snyder (Rosen, 2010), que estudava para se tornar professora primária, e publicou no MySpace uma foto na qual aparece numa festa 
com um chapéu de pirata bebendo com um copo de plástico. A sua universidade a acusou de promover o consumo de álcool entre seus alunos menores e the negou a habilitação ao ensino.

0 aspecto delicado é que essa pesquisa sobre a reputação na rede é feita com frequência pelos headhunters. Os departamentos de recursos humanos usam sistematicamente as informações obtidas na rede para avaliar candidatos a um emprego. Isso causa um problema inevitável quando o que emerge da rede contradiz o que o candidato diz sobre si mesmo. Não é a reputação na rede que garante o emprego, mas pode causar uma perda de oportunidade. Alguns departamentos de recursos humanos dizem que, na dúvida, se deixam levar pela e-reputação do candidato.

O tema torna-se ainda mais importante com a instituição de instrumentos (como Knout) que serviriam para medir a e-reputação, baseados num algoritmo que sintetiza, num único valor numérico, mais de 50 indicadores de atividades nas mídias sociais. Paralelamente têm início processos de manipulação com os quais os usuários “em observação” tomam providências específicas para aumentar o valor da sua própria reputação.

Seguem reflexões sobre dois casos particularmente interessantes. 0 primeiro concerne a um tal Marc L. Uma revista francesa (Le Tigre), muito engajada, queria mostrar como seria fácil, com as devidas pesquisas, achar muitíssimas indicações sobre uma pessoa, por exemplo, fotos, informações sobre a vida profissional e privada, todas públicas, com as quais criaria um perfil biográfico muito preciso e acurado. Em 2008, a revista publicou o perfil de Marc L. (Meltz 2008, Meltz, 2009). O fato teve imensa repercussão na imprensa francesa. A pessoa em questão apresentou queixa (e citou o problema do direito ao esquecimento) e obteve algumas modificações no perfil publicado, cancelando tudo o que tinha sido publicado na rede por ela mesma.
Mas, a essa altura, a sua reputação na rede já estava completamente comprometida!

Concluo com o caso de um pároco de Novara (e de Papai Noel!), porque é um caso que conheço pessoalmente e é, na minha opinião, um caso realmente típico.

Esse pároco, já não tão jovem, na época antes do Natal de 2008, disse às crianças de uma escola primária católica, durante uma missa, que "não se deve deixar que o Papai Noel roube o menino Jesus", considerado uma personagem do mundo da fantasia, como Cinderela e Branca de Neve.

Uma mãe comentou negativamente o ocorrido com um jornalista local, que, para chamar a atenção, publicou em um jornal local despretensioso uma notícia intitulada “Mataram Papai Noel". A notícia, considerada particularmente "curiosa", foi depois repetida pela agência italiana ANSA e, de acordo com essa última, pelo correspondente da BBC em Roma (Willey, 2008a). A essa altura, a mãe no caso havia sido transformada em "dezenas de pais" que protestaram. Em alguns dias, o número de páginas de internet citando o padre de Novara (e o mencionavam pelo nome: Dino Bottino!) passou de menos de 100 para mais de 10 mil, em mais de 20 línguas, incluindo islandês, estoniano, lituano, húngaro, albanês, chinês, vietnamita, indonésio, norueguês, sueco, polonês, russo, romeno, eslovaco etc, em sites no mundo inteiro, em mais de 40 países, desde as Ilhas Fiji, Nova Zelândia, Austrália, Timor Leste, Indonésia, Vietnã, China, até no Azerbaijão e Cazaquistão, passando pela África do Sul, Angola, até chegar ao Brasil (Willey, 2008b), Estados Unidos, Canadá e em uma boa parte da Europa. Tinha de tudo: desde católicos que acusavam o padre de Novara de ser o pior dos pedófilos até o outro extremo dos neopagãos - os Raelianos - que o defendiam!

São importantes as lições desse caso. $\mathrm{Na}$ internet, as notícias saltam de um site ao outro sem nenhum controle, completa- mente fora do contexto original, e em geral sem a fonte original. Quando a lenda é mais interessante do que a realidade, todos preferem a lenda! 0 papel dos comentários às notácias nesse caso é fundamental: muitas vezes são dezenas, mesmo no modesto caso citado. Também são importantes os blogs nessa multiplicação. Com certeza, os indícios na rede sobre essa pessoa permanecerão por muito tempo e, fora do círculo restrito de quem o conhece pessoalmente, ele será conhecido entre os que navegam na rede como "o padre católico que matou Papai Noel” (com a respectiva consequência de insultos, ameaças, sarcasmos...).

Os problemas da reputação na internet e do direito a ser esquecido estão se tornando cruciais para pessoas e organizações, especialmente no contexto de trabaIho e penal. Sobre a e-reputação das organizações, o caso do Tripadvisor é exemplar. 0 portal mais conhecido de aconselhamento aos viajantes já tem registrado inúmeros casos de manipulação intencional dos comentários (positivos e negativos) sobre hotéis, restaurantes etc. (Hickman, 2010).

\section{CONCLUSÕES}

Em síntese, qual é o papel da "ética da tecnologia da informação" (que inclui a Ética Digital, mas a transcende)? Da obra de Platão - Fedro - poderíamos assumir o que diz o rei do Egito a Theuth, o deus que inventou a primeira tecnologia da informação da humanidade, a escrita:

Quando, porém, chegou a ocasião da escrita, Theuth comentou: "Este é um ramo do conhecimento, rei, que tornará os Egípcios mais sábios e com melhor memória. $\mathrm{Na}$ verdade, foi descoberto o remédio da memória e da sabedoria”. Ao que o rei responde: "Ó engenhosíssimo Theuth, um homem é capaz de criar os fundamentos de uma arte, mas um outro deve julgar que parte de dano e de utilidade possui para quantos dela vão fazer uso. Ora tu, neste momento, como pai da escrita que és, apontas-lhe, 
por lhe quereres bem, os efeitos contrários àqueles de que ela é capaz."

Cada nova tecnologia da informação, com certeza, dá um passo adiante na história da civilização humana. E os seus “inventores" (e em geral quem tem interesse, especialmente econômico, na sua adoção e difusão) as elogiam, enfatizando seus benefícios, suas vantagens para a economia, para a sociedade, enfim, para a humanidade inteira. Mas alguém, um "rei do Egito", o que encarna a consciência critica, a ética da humanidade, antes que os danos em potencial se manifestem de maneira irreversível, ou caros demais para consertar, poderia - deveria! - poder "julgar qual parte de dano e da utilidade possui para quantos dela vão fazer uso" e divulgar essa consciência.

A evolução e difusão das tecnologias são realmente velozes, como vimos, portanto a consciência critica deve ficar alerta e tornar-se igualmente rápida. Tem se expandido a ideia (ou "mito") de que, graças às TIC e às redes, se poderia "restaurar" (?) a democracia direta. Para quem pensa assim, vai aqui o conselho da leitura do profético livro de Morozov (2011), The net delusion. Não devemos acalentar ilusões: além da potencialidade indiscutível a serviço da política (ou seja, da vida da polis) de Internet \& Co., devemos desmascarar a "ingenuidade" de muitas expectativas, para evitar que a Net Delusion afogue todas as esperanças e a fé nos milagres das Tecnologias da Informação e Comunicação.

\section{REFERÊNCIAS}

Bauman, Z. (2002). Society under Siege. United Kingdom: Polity.

Beck, U. (1992). Risk society: towards a new modernity (Vol. 17). London: Sage.

Berleur, J. (2002). Questions éthiques pour la gouvernance de l'Internet. Cahiers du numérique, 2(3), 17-33.

Carr, N. (2008). The big switch: rewiring the world - from Edison to Google (W. W. Norton, Trad.). São Paulo: Landscape. (Obra original publicada em 2008).

de Cindio F., Peraboni C. (2010). Cittadinanza, partecipazione e democrazia nella Network Society. In Di Guardo S., Maggiolini P., Patrignani N. (Eds.). Etica e responsabilità sociale delle tecnologie dell'informazione (Vol.2: Etica ed internet). Milan: Franco Angeli.

Fugini M.G., Maggiolini P., Pagamici B. (2005). Por que é difícil fazar o verdadero 'Governoeletrônico. Revista Produção,15(3), 300-309.

Guardo, S. Di, Maggiolini, P, \& Patrignani, N. (Eds.). (2010). Etica e responsabilità sociale delle tecnologie dell'informazione (Vol. 2). Milan: Franco Angeli.

Hickman, M. (2010). Hoteliers to take their revenge on TripAdvisor's critiques in court. The Independent. Recuperado em 12 de Maio, 2014, de http://www.independent.co.uk/travel/newsand-advice/hoteliers-to-take-their-revenge-ontripadvisors-critiques-in- court-2076417.html

Hinman L. (2005), Esse indicato est in Google: Ethical and Political Issues in Search Engines, International Review of Information Ethics, 3 (6), 19-25

Johns, A. (2009). Piracy: the intellectual property wars from Gutenberg to Gates. Chicago: University of Chicago Press.

Jonas, H. (1979). Das Prinzip Verantwortung. Frankfurt: Insel -Verlag

Maggiolini, P. (2010a). Tecnologie dell'informazione e società: niente di nuovo sotto il sole? In S. Di Guardo, P. Maggiolini, \& N. Patrignani (Eds.).
Etica e responsabilità sociale delle tecnologie dell'informazione (1). Milan: Franco Angeli.

Maggiolini, P. (2010b). L'etica nella società ed economia dell'informazione. In S. Di Guardo, P. Maggiolini, \& N. Patrignani (Eds.). Etica e responsabilità sociale delle tecnologie dell'informazione (Vol. 1). Milan: Franco Angeli.

Mayer-Schönberger, V. (2009). DELETE: the virtue of forgetting in the digital age. Princeton: Princeton University Press.

Meltz R. (2008): Marc L.***. Le Tigre, 28 Recuperado em 12 de Maio, 2014, de www.letigre.net/Marc-L.html

Meltz R.. (2009): Marc L. Genèse d'un buzz médiatique. Le Tigre, 30, Recuperado em 12 de Maio, 2014, de http://www.le-tigre.net/Marc-LGenese-d-un-buzz-mediatique.html

Morozov, E. (2011). The net delusion: the dark side of internet freedom. New York: PublicAffairs.

Patrignani, N. (2009). Computer ethics. Un quadro concettuale. Mondo Digitale, Recuperado em 28 de junho, 2014, de http://www.mondodigitale.net/Rivista/o9_ numero_3/Patrignani_p_55_63.pdf

Ricoeur, P. (1955). Le socius et le prochain. In Histoire et verité. Paris: Seuil.

Rosen J. (2010). The web means the end of forgetting, New York Times, Recuperado em 28 de junho, 2014, de http://www.nytimes. com/2010/07/25/magazine/25privacy-t2. $h t m l$ ?pagewanted=all\&_r $=0$

Schelling, T. C. (1978). Micromotives and macrobehavior. New York: W. W. Norton and Co.

Willey, D. (2008a). Priest 'ruins Christmas' for kids. $B B C$ News. Recuperado em 28 de junho, 2014, de http://news.bbc.co.uk/2/hi/ europe/7798480.stm

Willey, D. (2008b). Padre irrita pais ao revelar que Papai Noel não existe. $B B C$ News. Recuperado em 28 de junho, 2014, de http:// www.bbc.co.uk/portuguese/reporterbbc/ story/2008/12/081224_padre_noel.shtml 